EXTENDED REPORT

\title{
Role of peptidoglycan subtypes in the pathogenesis of bacterial cell wall arthritis
}

\author{
E Šimelyte, M Rimpiläinen, X Zhang, P Toivanen
}

Ann Rheum Dis 2003:62:976-982

See end of article for authors' affiliations

Correspondence to: Professor P Toivanen, Department of Medical Microbiology, Turku University, Kiinamyllynkatu 13, FIN-20520 Turku, Finland; paavo.toivanen@utu.fi

Accepted

7 February 2003 btrains of rats after a single Background: Bacterial cell wall (CW) arthritis develops in susceptible strains of rats after a single
intraperitoneal injection of the $\mathrm{CW}$ from certain bacterial species, both pathogenic and non-pathogenic. For the development of chronic bacterial CW arthritis, the structure of the bacterial peptidoglycan (PG) has been found to be decisive.

Objective: To define the role of PG subtypes in the pathogenesis of chronic bacterial CW arthritis. Method: Arthritis was induced with CWs of Lactobacillus plantarum, $L$ casei $B, L$ casei $C$, and $L$ fermentum. Gas chromatography-mass spectrometry was used to measure the presence of CW derived muramic acid in the liver and to determine PG subtypes. CWs were also tested for their resistance to lysozyme in vitro.

Results: These results and those published previously indicate that PGs of CWs which induce chronic arthritis, no matter whether they were derived from strains of Streptococcus, Bifidobacterium, Collinsella, or Lactobacillus, all have lysine as the third amino acid of the PG stem peptide, representing PG subtypes $A 3 \alpha$ and $A 4 \alpha$. Those strains which induce only transient acute arthritis or no arthritis at all do not have lysine in this position, resulting in different PG subtypes.

Conclusions: In vivo degradation of only those PGs with the subtypes $A 3 \alpha$ and $A 4 \alpha$ leads to the occurrence of large CW fragments, which persist in tissue and have good proinflammatory ability. CWs with other PG subtypes, even if they are lysozyme resistant, do not cause chronic arthritis, because the released fragments are not phlogistic. It is emphasised that a variety of microbial components not causing inflammation have been found in animal and human synovial tissue.
$\mathrm{T}$ he cell wall (CW) of Gram positive bacteria has a peptidoglycan (PG) as a major component. PG polymer is composed of alternating $N$-acetylmuramic acid and $\mathrm{N}$-acetylglucosamine sugar chains with cross-linking peptide chains containing D- and L-amino acids. ${ }^{1}$ In the CW, polysaccharides (PS) and teichoic acids are covalently bound to PG. These structures in the CW complex, or alone, are biologically active, with immunoadjuvant or slow wave sleep promoting activity. ${ }^{2}$ During Gram positive infections, PG can activate complement ${ }^{3}$ and granulocytes, ${ }^{4}$ and up regulate expression of adhesion molecules on the endothelial cells. ${ }^{4}$ In vitro, PG is known to induce production of the proinflammatory cytokines interleukin 1, interleukin 6, tumour necrosis factor $\alpha(\mathrm{TNF} \alpha)$, and monocyte chemoattractant protein-1 (MCP-1) by monocytes. ${ }^{5-8}$ Bacterial CWs are digested by a number of PG degrading hydrolytic enzymes, including lysozyme, and the amounts of active CW fragments released depend on the activity of these PG hydrolases. ${ }^{89}$

It has been suggested that PG plays a part in the pathogenesis of chronic inflammation such as rheumatoid arthritis. This hypothesis is based on experimental results obtained after systemic injection of high molecular weight PG-PS complexes, resulting in chronic synovial inflammation. CW components isolated from a variety of Gram positive bacterial species are disease inducing. ${ }^{10} \mathrm{~A}$ single injection of bacterial CW causes chronic erosive arthritis ${ }^{11-14}$ and hepatic granulomas $^{14}{ }^{15}$ in susceptible rat strains. On the other hand, purified PG-PS derived from normal human enteric flora can also induce chronic arthritis ${ }^{16}$ and granulomatous enterocolitis $^{18}$ in the rat. The bacterial species used include Lactobacilli, ${ }^{13}{ }^{19}$ Collinsella, Eubacteria, ${ }^{20}{ }^{21}$ and Bifidobacteria. ${ }^{14}{ }^{17}$ It has also seemed that CWs from closely related bacteria within a single genus, including Streptococcus, ${ }^{22}$ Lactobacillus, ${ }^{19}$ as well as Collinsella and Eubacterium, ${ }^{8021}$ may be either arthritogenic or non-arthritogenic. Therefore we aimed at determining the factors decisive for the arthritogenicity of the bacterial CW. ${ }^{813} 142123-26$

The differences in arthritogenicity between different CWs seem to depend on the chemical structure of PG. ${ }^{132126}$ Variations of the PG peptide moiety occur in the mode of cross linkage, the interpeptide bridge, and the peptide subunit. Based on the anchorage point of the cross linkage to the peptide subunit, the primary structure of PG is divided into type A (cross linkage between position 3 and 4 ) and type B (cross linkage between position 2 and 4); these are further classified into different subtypes depending on the type/presence of the connecting interpeptide bridges and the amino acid in the third position of the PG peptide subunit.

In this study we aimed at elucidating the critical role of PG subtypes in the pathogenesis of chronic bacterial CW arthritis. For this purpose, arthritogenicity and concentrations in the liver of the CWs of four Lactobacillus strains were studied in relation to the PG subtypes, and the results obtained were compared with those already published. Additionally, we also evaluated the lysozyme resistance of different PGs.

\section{MATERIALS AND METHODS}

\section{Bacterial strains}

The following strains of Lactobacillus were used: L plantarum ATCC $4008, L$ casei C ATCC 25302 , L casei B ATCC 11578 , and $L$ fermentum ATCC 14931. These strains were purchased from the American Type Culture Collection, Rockville, MD. All bacteria

Abbreviations: CW, cell wall; GC-MS, gas chromatography-mass spectrometry; IP, intraperitoneally; MCP, monocyte chemoattractant protein; PBS, phosphate buffered saline; PG, peptidoglycan; PS polysaccharides; TNF $\alpha$, tumour necrosis factor $\alpha$ 
Table 1 Characterisation of CW doses used in studies on bacterial CW arthritis

\begin{tabular}{|c|c|c|c|c|c|c|c|}
\hline \multirow[b]{2}{*}{ Origin of $\mathrm{CW}$} & \multicolumn{3}{|l|}{ Dose } & \multicolumn{2}{|c|}{ Content of } & \multirow[b]{2}{*}{$\begin{array}{l}\text { Chronic } \\
\text { arthritis }\end{array}$} & \multirow[b]{2}{*}{ Reference } \\
\hline & $\begin{array}{l}\mathrm{CW} \\
(\mathrm{mg})^{*}\end{array}$ & $\begin{array}{l}\text { Muramic } \\
\text { acid }(\mathrm{mg})^{*}\end{array}$ & $\begin{array}{l}\text { Total } \\
\text { carbohydrate }(\mathrm{mg})^{*}\end{array}$ & $\begin{array}{l}\text { Muramic } \\
\text { acid } \dagger\end{array}$ & $\begin{array}{l}\text { Total } \\
\text { carbohydrate } \dagger\end{array}$ & & \\
\hline \multirow[t]{2}{*}{ L plantarum ATCC 4008} & 38.7 & ND & 6.0 & ND & 15.5 & - & Lehman et al, $1985^{19}$ \\
\hline & 24.0 & 1.9 & 6.9 & 8.0 & 28.9 & $?$ & Present study \\
\hline \multirow[t]{3}{*}{ L casei C ATCC 25302} & 42.9 & ND & 6.0 & ND & 14.0 & - & Lehman et al, $1985^{19}$ \\
\hline & 24.4 & 1.0 & $5.0 \ddagger$ & 4.0 & ND & + & Simelyte ef al, $2000^{13}$ \\
\hline & 24.0 & $1.0 \S$ & 4.9 & ND & 20.5 & + & Present study \\
\hline \multirow[t]{3}{*}{ L casei B ATCC 11578} & 25.0 & ND & 6.0 & ND & 24.0 & + & Lehman et al, $1985^{19}$ \\
\hline & 16.2 & 0.9 & $5.0 \ddagger$ & 5.3 & ND & + & Šimelyte ef al, $2000^{13}$ \\
\hline & 8.0 & $0.4 \S$ & 2.5 & ND & 30.9 & + & Present study \\
\hline \multirow{3}{*}{ L fermentum ATCC 14931} & 21.0 & ND & 6.0 & ND & 28.6 & - & Lehman et al, $1985^{19}$ \\
\hline & 27.0 & 1.6 & $5.0 \ddagger$ & 6.0 & ND & - & Simelyte ef al, $2000^{13}$ \\
\hline & 8.0 & $0.5 \S$ & 1.5 & ND & 18.5 & - & Present study \\
\hline \multirow[t]{2}{*}{ C aerofaciens ATCC 25986} & 16.7 & 2.5 & ND & 15.0 & ND & + & Kool et al, $1992^{54}$ \\
\hline & 20.0 & 0.4 & 11.8 & 1.9 & 58.9 & + & Zhang et al, $2000^{21}$ \\
\hline
\end{tabular}

were grown by the bioproduction unit in the Department of Biochemistry and Food Chemistry, Turku University.

\section{CW preparations}

Bacterial CWs were isolated and purified as described previously. ${ }^{1323} 27$ To separate 10P (pellet) and loS (supernatant) fractions, ${ }^{28}$ the $\mathrm{CW}$ preparations were centrifuged at $10000 \mathrm{~g}$ at $4^{\circ} \mathrm{C}$ for 30 minutes. The protein content determined by the Lowry method ${ }^{29}$ in the $10 \mathrm{~S}$ fractions was $8.0 \%, 11.6 \%$, $13.1 \%$, and $7.9 \%$ per dry weight for $L$ plantarum, $L$ casei $C, L$ case $i$ $\mathrm{B}$, and $L$ fermentum, respectively. The total carbohydrate amount determined by the phenol-sulphuric acid method ${ }^{30}$ in these preparations was $28.9 \%, 20.5 \%, 30.9 \%$, and $18.5 \%$ per dry weight, respectively. To exclude endotoxin contamination, the loS preparations were tested by the E-TOXATE Limulus amebocyte lysate test (Sigma Chemical Co, MO); all tests were negative, with endotoxin concentrations $<0.12 \mathrm{EU} / \mathrm{ml}$. The sensitivity of the test was $0.05-0.1 \mathrm{EU} / \mathrm{ml}$. For sterility, the fractions were tested by bacterial culture on agar. The 10S fractions were used in all experiments.

\section{Chemical structure of $L$ plantarum $C W$}

To determine the chemical composition, PG was isolated from $L$ plantarum according to a previously described protocol. ${ }^{31}$ Briefly, the lyophilised IOS fraction of CW was extracted with $10 \%$ trichloroacetic acid at $60^{\circ} \mathrm{C}$ for 4 hours. The suspension was centrifuged at $38800 \mathrm{~g}$ at $4^{\circ} \mathrm{C}$ for 20 minutes, and washed three times with distilled water. The pellet contained the $L$ plantarum PG fraction. The carbohydrates and amino acids of the PG were quantified with the HP 5890A gas chromatograph (Hewlett-Packard, Palo Alto, CA), equipped with a HewlettPackard column, $30 \mathrm{~m} \times 0.25 \mathrm{~mm}$ internal diameter (HewlettPackard, Palo Alto, CA), coupled directly to a VG TRIO-1 mass spectrometer (VG Instruments, Manchester, UK) as described previously. ${ }^{13212632}$ The molecules were ionised by the electron impact method and analysed in a selected ion mode using positive ions. Briefly, sugars and amino sugars were analysed as alditol acetate derivatives with mannose and $N$-methyl-Dglucamine as internal standards, and amino acids as butyl heptafluorobutyl derivatives with norleucine, methionine, and tryptophan as internal standards, respectively. ${ }^{33}$ The concentration of the lowest standard used was $2.5 \mathrm{ng}$.

\section{Rats}

Pathogen-free inbred female LEW/SsNHsd rats (from the 202B colony at Harlan Sprague Dawley, Inc, Indianapolis, IN), weighing on average $105 \mathrm{~g}$, were used. The animals were kept in Macrolon III cages with disposable filter tops (Scanbur,
Denmark); all handling was performed in a laminar-flow hood. The rats were given autoclaved standard diet and water freely. Before the experiments the animals were allowed to adapt to the local environment for one week. The animal experiments were performed in compliance with national and international laws and policies, and were approved by the Institutional Committee for Animal Research.

\section{Arthritis induction and clinical evaluation}

Two separate experiments were done: L plantarum and $L$ casei $C$ were used for the first experiment, and $L$ casei B with $L$ fermentum for the second. On day 0 , each of the four groups of rats $(n=30-32)$ was injected intraperitoneally (IP) with sterile phosphate buffered saline (PBS) suspensions of CW preparations ( $3 \mathrm{ml}$ for each rat). The doses used were chosen on the basis of previously published results (table 1). In the first experiment, with $L$ plantarum and $L$ casei $C$ the injection dose was $24 \mathrm{mg}$ of CW dry weight per $100 \mathrm{~g}$ of rat body weight, whereas in the second experiment with $L$ case $\mathrm{B}$ and $L$ fermentum the dose was $8 \mathrm{mg}$. Such doses, based on the total carbohydrate concentrations determined in each $\mathrm{CW}$, correspond with a carbohydrate content of $7.3 \mathrm{mg}, 5.2 \mathrm{mg}, 2.6 \mathrm{mg}$, and 1.6 mg per rat for $L$ plantarum, $L$ casei $C, L$ casei $\mathrm{B}$, and $L$ fermentum, respectively.

Control rats $(n=15)$ were injected IP with $3 \mathrm{ml}$ of PBS alone. To monitor the development of arthritis, the front and hind paws were scored with a naked eye inspection daily for the first 10 days, and later three times a week. The arthritic symptoms were graded from 0 to 4 , based on the degree of erythema, oedema, and functional disorder of the ankle and metatarsal joints (wrist and metacarpal joints), by two independent observers as described previously. ${ }^{13} 212326$ In the rats injected with $L$ plantarum or $L$ casei $C$ the development of arthritis was also monitored by caliper (resolution $0.05 \mathrm{~mm}$; Mitutoyo Asia Pacific Pte Ltd, Japan) measurement of paw swelling; the results were found to agree with those obtained by visual scoring. Rats were killed at different times by cardiac puncture bleeding under methoxyfluorane (Metofane; Pitman-Moore, Inc, Washington Crossing, NJ) anaesthesia.

\section{Liver samples}

Four to six rats of each group were killed 1, 3, 7, 14, and 28 days after the CW injection. On each occasion, livers from these and from three control rats were collected. The organs were weighed and stored at $-20^{\circ} \mathrm{C}$ until used. To prepare the liver samples, $5 \mathrm{ml}$ of sterile water was added to each sample before homogenisation with an Ultra Turrax T25 tissue homogeniser (Janke and Kunkel, IKA, Labortechnik, Staufen, 
Germany). The final volume was measured, and the suspensions were analysed by gas chromatography-mass spectrometry (GC-MS) for the muramic acid content. When necessary, liver suspensions were diluted with distilled water to 1:3, 1:5, $1: 10$, or 1:30. The presence of muramic acid was determined in the whole liver for each rat.

\section{Sample preparation for GC-MS}

Muramic acid content in the liver samples was analysed as the trifluoroacetylated methylglycoside derivative by GC-MS, using the chemical ionisation mode with negative ion detection as previously described.$^{34}$ To obtain the muramic acid standard for the negative chemical ionisation, Elimosum (ATCC 8486, American Type Culture Collection, Rockville, MD) CW suspension, isolated as described, ${ }^{21}$ was used. The muramic acid concentration of the E limosum CW was determined by GC-MS using the electron impact ionisation as described previously. ${ }^{33}$ The standard curve was linear with muramic acid (Sigma Chemical Co, St Louis, MO) concentrations from 10 to $130 \mathrm{ng}$ (injected amount).

For the negative chemical ionisation, samples from liver suspensions and $E$ limosum $\mathrm{CW}$ suspension were evaporated to dryness under a stream of nitrogen at $40^{\circ} \mathrm{C}$. The samples were then methanolysed under a nitrogen atmosphere at $85^{\circ} \mathrm{C}$ for 24 hours in $2 \mathrm{ml}$ of $4 \mathrm{M}$ methanolic hydrochloric acid. Hexane (SupraSolv purity, Merck and Co, Inc, NJ) extraction (3 ml) was performed for the methanolysate. The internal standard $\mathrm{N}$-methyl-D-glucamine (Sigma Chemical Co, St Louis, MO), dissolved in methanol (SupraSolv purity, Merck and Co, Inc, $\mathrm{NJ}$ ), was dried under nitrogen atmosphere at $40^{\circ} \mathrm{C}$ and further processed in the same way as the samples. After derivatisation, samples were diluted with $400 \mu \mathrm{l}$ of toluene (SupraSolv purity, Merck KGaA, Darmstadt, Germany), $50 \mu$ aliquots were put into the sample vials and diluted with derivatised internal standard $(50 \mu \mathrm{l})$, and $\mathrm{l} \mu \mathrm{l}$ was injected into the GC-MS system.

Glassware used was first treated with DECON 90 (Decon Laboratories Ltd, Sussex, UK), and 10\% DECONEX 11 UNIVERSAL (Borer Chemie Ab, Zuchwil, Switzerland), rinsed with water (2-6 times) between the steps, heated at $170^{\circ} \mathrm{C}$ for two hours, before autoclaving for 20 minutes.

\section{GC-MS of muramic acid in the liver}

The GC-MS analyses were performed with a gas chromatograph (model 6890, Hewlett-Packard, Little Falls, DE) coupled to a mass selective detector (model 5973, Hewlett-Packard, Palo Alto, CA). The GC-MS apparatus was equipped with an HP-5MS capillary column (30 m length, $250 \mu \mathrm{m}$ diameter, $0.25 \mu \mathrm{m}$ film thickness, Agilent Technologies, Palo Alto, CA). Helium (purity $>99.5 \%$ ) served as the carrier gas, and isobutane (purity 99.5\%) as the reagent gas. The starting temperature of the oven $\left(80^{\circ} \mathrm{C}\right)$ was held for 2.5 minutes, and programmed at the rate of $8^{\circ} \mathrm{C} / \mathrm{min}$ to a final temperature of $210^{\circ} \mathrm{C}$, where it was held for one minute. As a post-run step the oven was heated to $300^{\circ} \mathrm{C}$ for seven minutes. A pulsed splitless injection mode with a slow plunger speed was used with a 2.5 minute pulse time. Selected ion monitoring with negative chemical ionisation and with computerised standardisation, including internal standards, was used for the measurement of muramic acid according to specific guidelines, as described in the Hewlett-Packard G1701AA MS Chemstation workbook (DOS series). A molecular ion with mass/charge ratio $(\mathrm{m} / \mathrm{z})$ of 567 was used as the target ion, and those with $\mathrm{m} / \mathrm{z}=480$ and $\mathrm{m} / \mathrm{z}=453$ were used as qualifier ions. The detection limit was $1 \mathrm{pg}$, defined as the amount of muramic acid giving a signal to noise ratio of about 20-30 (peak to peak noise). Samples from the same liver suspension were analysed in two to three different runs, always at least in triplicate. The same chemical ionisation mode with a negative ion detection method was used to analyse the muramic acid content in all four Lactobacillus 10S fractions.

\section{Degradation of CWs by lysozyme}

All the 10S CW fractions from each Lactobacillus strain were tested for lysozyme (Sigma, St Louis, MO) sensitivity, as described previously. ${ }^{135}$ The assays were performed in triplicate. A CW was considered lysozyme resistant when degradation of the $10 \mathrm{~S}$ preparation was $<30 \%$.

\section{Statistics}

The differences between study groups were compared by Mann-Whitney $U$ test for unpaired data and Wilcoxon matched pairs test for paired data. Values of $p<0.05$ were considered significant.

\section{RESULTS}

\section{PG subtypes}

Here we determined the PG subtype of L plantarum ATCC 4008 , which was previously unknown. For this purpose the content of carbohydrates and amino acids in the $L$ plantarum CW preparation used was determined. In accordance with the other strains of $L$ plantarum studied, ${ }^{1}$ the results obtained show that the L plantarum CW used has diaminopimelic acid, alanine and glutamine as PG amino acids, indicating the PG subtype Al $\gamma$ (table 2; fig 1). The structures of the three other PGs used here are also already known ${ }^{13} 36{ }^{37}$; they are presented in fig 1 , with subtype $A 4 \alpha$ for the other arthritogenic $L$ case $i$ strains used and the subtype $A 4 \beta$ for the non-arthritogenic $L$ fermentum strain. It should also be noted that $L$ plantarum does not contain rhamnose (table 2 ), even though the presence of rhamnose has not been found to be related to the arthritogenicity or non-arthritogenicity of bacterial CWs ${ }^{13}{ }^{20}$ in contrast with a previous suggestion. ${ }^{16}{ }^{19}$

\section{Arthritogenicity in vivo}

To determine the arthritogenicity of the four Lactobacillus CWs used, two separate experiments were carried out. In the first experiment with $L$ plantarum and $L$ casei $\mathrm{C}$, rats were injected IP with $24 \mathrm{mg}$ of CW dry weight per $100 \mathrm{~g}$ of body weight. This dose of $L$ casei $\mathrm{CW}$ has previously been found to be arthritogenic, ${ }^{13}$ and for $L$ plantarum CW, even higher doses have been reported to be non-arthritogenic. ${ }^{19}$ On day 2 after CW injection 5/32 rats had died in the $L$ casei $C$ group, and $1 / 31$ in the $L$ plantarum group. Therefore for the second experiment

Table 2 Chemical composition of the $L$ plantarum ATCC $4008 \mathrm{CW}$. Components of the PG are indicated in bold

\begin{tabular}{|c|c|}
\hline Component & 10S fraction of the CW \\
\hline Carbohydrates, total & $16.5^{*}$ \\
\hline Rhamnose & $<0.4$ \\
\hline Glucose & 0 \\
\hline Galactose & $+\dagger$ \\
\hline Mannose & + \\
\hline Fucose & + \\
\hline$N$-acetylmuramic acid & 8.1 \\
\hline $\mathrm{N}$-acetylglucosamine & 8.0 \\
\hline Amino acids, total & 79.5 \\
\hline Diaminopimelic acid & 24.8 \\
\hline Alanine & 19.8 \\
\hline Glutamic acid/glutamine & 12.2 \\
\hline Isoleucine & 4.3 \\
\hline Lysine & 3.6 \\
\hline Aspartic acid/asparagine & 3.4 \\
\hline Threonine & 3.1 \\
\hline Valine & 2.7 \\
\hline Glycine & 2.2 \\
\hline Proline & 2.0 \\
\hline Tyrosine & 1.4 \\
\hline Total & 96.0 \\
\hline
\end{tabular}

*Values are expressed as percentage of PG dry weight; †detected, not measured. 
$\rightarrow$ Lysozyme ( $\beta-N$-acetylglucosaminidase) $\rightarrow N$-acetylmuramyl---alanine-amidase
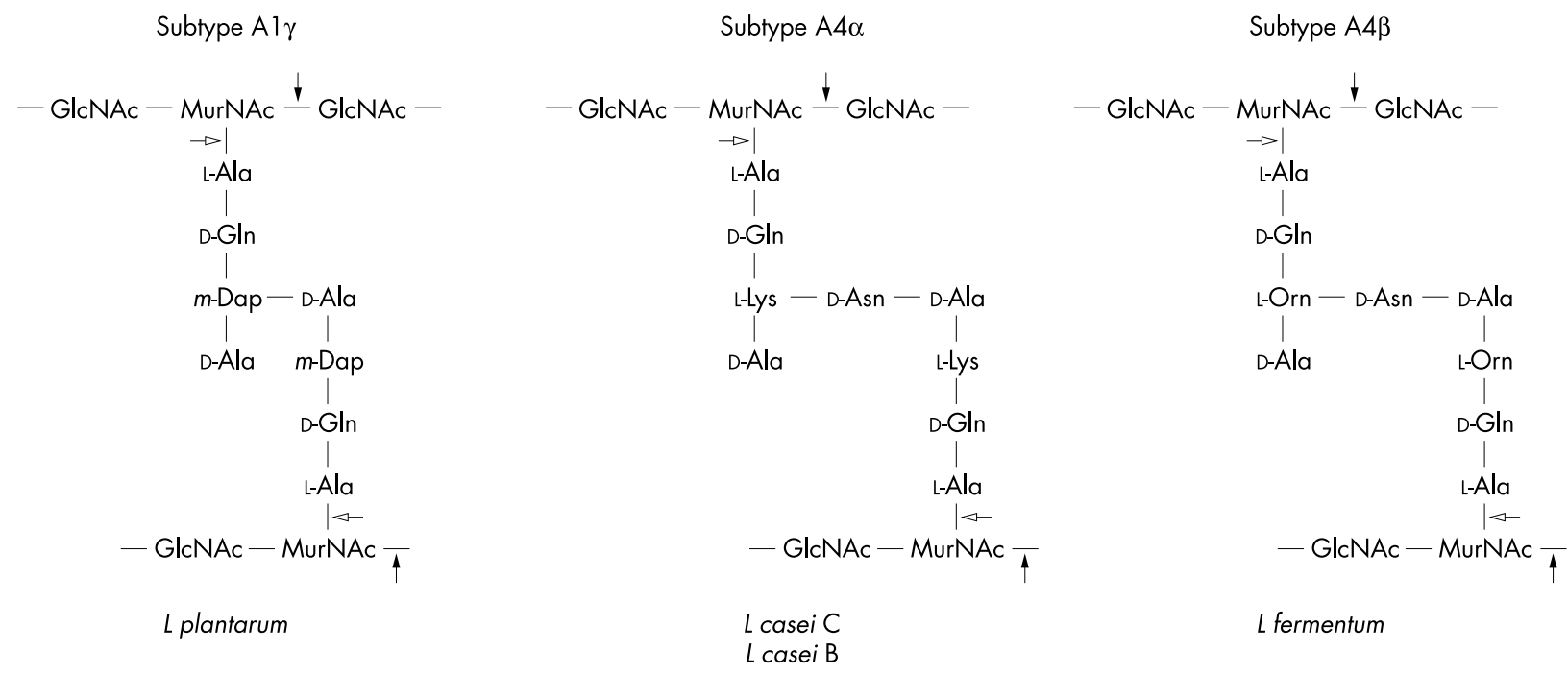

Figure 1 PG structures in the Lactobacillus strains used. The $L$ plantarum belongs to the D-glutamine- $m$-diaminopimelic acid-D-alanine subtype $(A 1 \gamma)$, the two $L$ casei share the L-lysine-D-asparagine subtype $(A 4 \alpha)$, whereas $L$ fermentum has the subtype l-ornithine-D-asparagine (A4 $\beta)$. The enzymes degrading PG cleave specific bonds: lysozyme ( $\beta$ - $N$-acetylglucosaminidase) and $N$-acetylmuramyl-t-alanine-amidase.

with $L$ casei $\mathrm{B}$ and $L$ fermentum, a lower dose of $8 \mathrm{mg}$ of CW dry weight per $100 \mathrm{~g}$ of body weight was chosen. In the preliminary experiments this dose of $L$ casei B CW was found to be arthritogenic, and for $L$ fermentum CW considerably higher doses were non-arthritogenic ${ }^{13} 19$ (table 1). It should also be noted that the amount of muramic acid injected into each rat equalled that previously used to induce chronic CW arthritis with Collinsella aerofaciens ${ }^{21}$ (table 1).

In contrast with the previous findings indicating the non-arthritogenicity of $L$ plantarum $\mathrm{CW},{ }^{19}$ we observed arthritis which lasted for at least 28 days after a single IP injection of $L$ plantarum CW (fig 2 ). Injection of CWs from $L$ casei $C$ and $L$ casei $\mathrm{B}$ also resulted in development of arthritis lasting for at least 28 days, whereas $L$ fermentum induced only a mild acute arthritis, which completely subsided in 10 days; these findings were as expected. Rats injected with PBS alone did not develop any signs of arthritis.

\section{Muramic acid in the liver}

The presence of CW in the liver was studied on days 1, 3, 7, 14, and 28 by measuring the muramic acid content. This amino sugar is a component of the PG backbone and is not synthesised by mammalian cells. The detection limit of our method was 1 pg (the amount injected into the chromatograph column). Because muramic acid concentrations in the liver are known to reflect those found in the spleen, ${ }^{813}$ only liver samples were here collected and analysed.

CWs of both $L$ casei ( C and B) accumulated in the liver similarly, persisting on day 28 with $20 \%$ of the injected muramic acid remaining in the liver, in contrast with the nonarthritogenic $L$ fermentum, which accumulated in the liver only to a small extent and finally cleared away, with $<5 \%$ of the total dose injected detectable on day 28 (fig 3 ). Deposition of $L$ plantarum CW was highest on days 3 and 7 , and reflected the occurrence of acute arthritis, whereas on days 14 and 28 it was

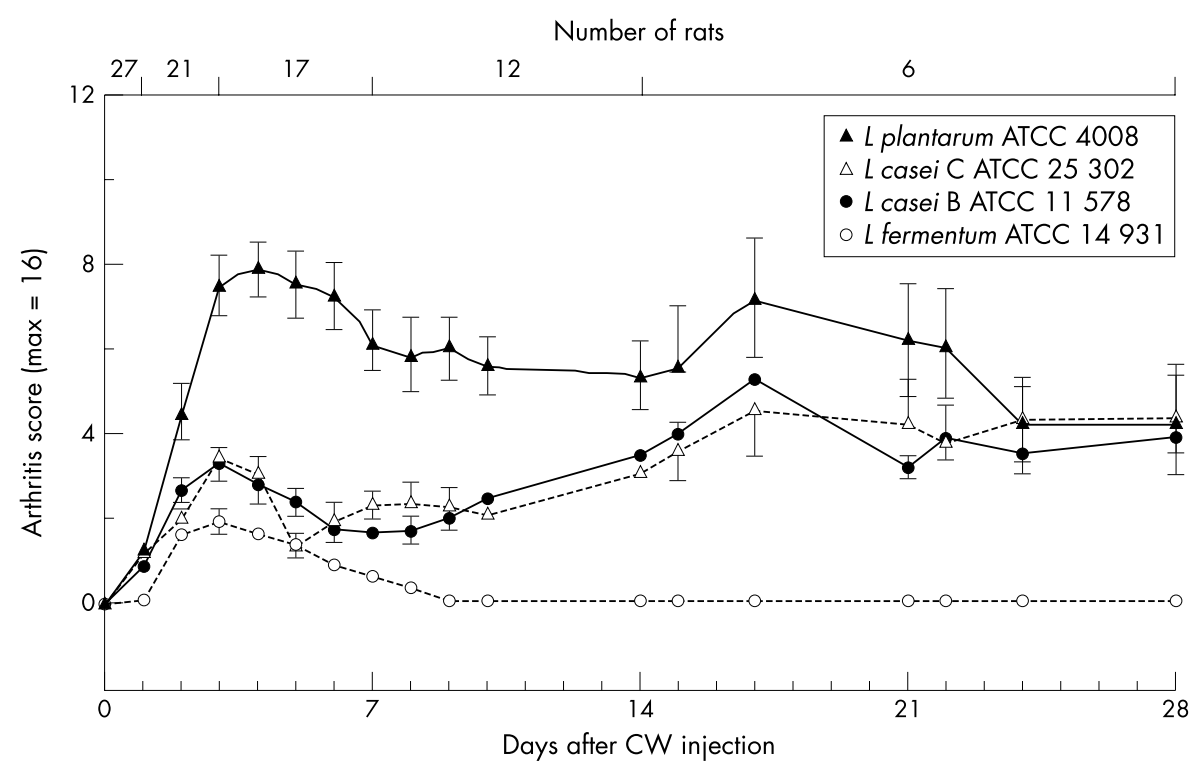

Figure 2 Development of arthritis in rats injected IP with Lactobacillus $\mathrm{CW}$. The injection dose was $24 \mathrm{mg}$ of CW dry weight $/ 100 \mathrm{~g}$ of rat body weight for L plantarum ATCC 4008 or $L$ casei C ATCC 25302, and $8 \mathrm{mg}$ for $L$ casei B ATCC 11578 or $L$ fermentum ATCC 14931. The arthritis score is calculated as a mean value (SEM) for the number of rats indicated at the top. Rats which died on day 2 are excluded from this figure. 


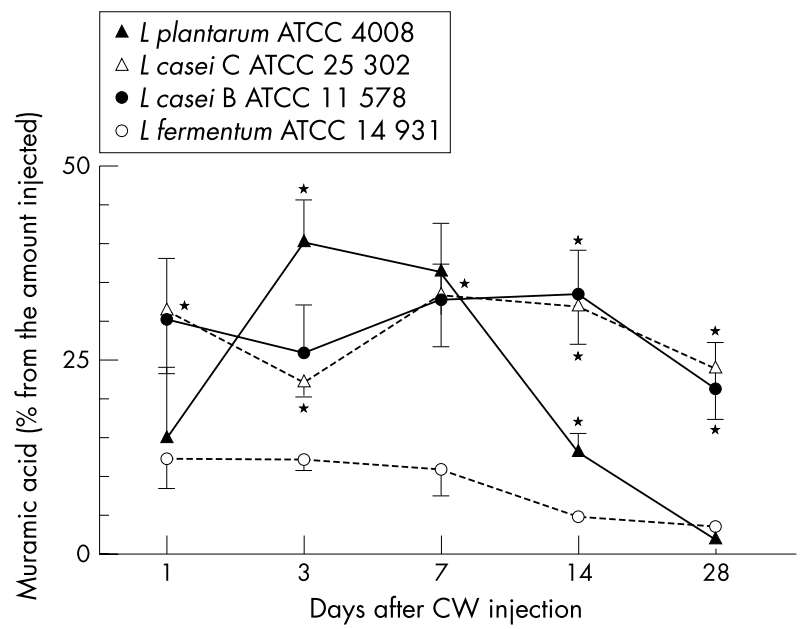

Figure 3 Muramic acid content in rat liver analysed by GC-MS. On day 0 rats were injected IP with CW from L plantarum ATCC 4008 $L$ casei C ATCC 25302, L casei B ATCC 11578 , or $L$ fermentum ATCC 14931. The muramic acid levels are given as the mean value (SEM) for four to six rats. Asterisks indicate significant differences $(p<0.05)$ when the rats injected with $L$ plantarum, $L$ casei $C$ or $L$ casei $B C W s$ were compared with those injected with $L$ fermentum $C W$. Significance is shown separately for each day of analysis.

close to the values of $L$ fermentum $C W$ - that is, close to 0 on day 28. In other words, CWs of the two strains of $L$ casei known to be arthritogenic persisted in the liver, which was not found with the CWs of $L$ fermentum and $L$ plantarum. Livers of the rats injected with PBS alone were found to be muramic acid negative.

\section{Resistance to lysozyme}

Incubation for 24 hours with the lysozyme did not produce any degradation of $L$ casei $\mathrm{C}$ or $L$ casei B CWs, whereas CWs of $L$ fermentum and $L$ plantarum were lysozyme sensitive, with a $57 \%$ and $48 \%$ decrease in OD at $560 \mathrm{~nm}$, respectively.

\section{DISCUSSION}

Table 3 summarises the ability of different bacterial CWs to induce chronic arthritis in relation to the PG subtypes, based on the present results and those published by us and by others previously. It appears that PGs of bacterial strains inducing chronic arthritis in the rat, no matter whether they are derived from strains of Streptococcus, Bifidobacterium, Collinsella, or Lactobacillus, have lysine as the third amino acid of the PG stem peptide, representing PG subtypes $A 3 \alpha$ or $A 4 \alpha$. On the other hand, all those strains which induce only a transient acute arthritis or no arthritis at all do not have lysine in this position; the position is occupied instead either by ornithine or diaminopimelic acid, resulting in a variety of PG subtypes. Most interesting is a pair of almost identical strains of Collinsella aerofaciens (formerly Eubacterium aerofaciens ${ }^{38}$ ), one of them causing chronic arthritis with lysine in the critical position of the PG stem peptide, and the other with ornithine in the same position, and causing only a slight acute, transient arthritis. ${ }^{82}$ All these findings strongly suggest that the PG structure with lysine as the third amino acid in the stem peptide is required for induction of chronic bacterial CW arthritis. The only potential exception, which does not fit into the above suggestion, is L plantarum CW (table 3 ). However, the lack of long term tissue accumulation, as seen in the present study, indicates that arthritis caused by this CW cannot be long lasting.

Several previous observations support our suggestion that PG subtypes $\mathrm{A} 3 \alpha$ and $\mathrm{A} 4 \alpha$ with lysine as the third amino acid in the stem peptide are more arthritogenic than other PG subtypes. On the basis of studies on adjuvant arthritis evidence has been presented that structural variations of the chemically defined PG subunits result in drastic changes of the arthritogenic ability, ranging from complete nonarthritogenicity to production of severe arthritis in high frequency. ${ }^{39} 40$ Kohashi et al compared the arthritogenicity of PGs from the CWs of Staphylococcus aureus and L plantarum. ${ }^{39}$ They concluded that a PG subunit with a chain length of two disaccharide units was the minimal structure responsible for arthritogenicity. Consequently, muramyl dipeptide was defined as the minimal arthritogenic structure in adjuvant arthritis. ${ }^{40}$ Variation of the third amino acid of the stem peptide has been shown to change the biochemical activity of PG fragments. In studies on subarachnoidal inflammation in the rabbit, PG fragments with lysine in position three were found to be highly inflammatory ${ }^{41-43}$ Also, branched stem peptides with lysine in position three, isolated from Streptococcus

Table 3 Arthritogenicity of bacterial CWs in relation to PG subtype and resistance to lysozyme in vitro

\begin{tabular}{|c|c|c|c|c|c|c|c|c|c|c|c|}
\hline \multirow[b]{3}{*}{ Origin of CW } & \multicolumn{2}{|c|}{ Chronic arthritis in rat } & \multicolumn{6}{|c|}{ PG structure } & \multirow[b]{3}{*}{ Reference } & \multicolumn{2}{|c|}{ Resistance to lysozyme } \\
\hline & \multirow[b]{2}{*}{$+/-$} & \multirow[b]{2}{*}{ Reference } & \multicolumn{5}{|c|}{ Stem peptide amino acids } & \multirow[b]{2}{*}{ Subtype } & & \multirow[b]{2}{*}{$+1-$} & \multirow[b]{2}{*}{ Reference } \\
\hline & & & 1 & 2 & 3 & $\rightarrow$ & 4 & & & & \\
\hline Lactobacillus casei B ATCC 25303 & + & 19 & Ala & Glu & Lys & Asp & Ala & $\mathrm{A} 4 \alpha$ & 13,36 & + & 13,19 \\
\hline - casei B ATCC 11578 & + & $19,27, \mathrm{PS}$ & Ala & Glu & Lys & Asp & Ala & $\mathrm{A} 4 \alpha$ & 1,13 & + & 13,27, PS \\
\hline - casei C ATCC 25302 & $+{ }^{*}$ & 13, PS & Ala & Glu & Lys & Asp & Ala & $\mathrm{A} 4 \alpha$ & $13,36,37$ & + & 13,19, PS \\
\hline Streptococcus pyogenes D-58 (group A) & + & $11,16,35$ & Ala & Glu & Lys & Thr & Ala & $\mathrm{A} 3 \alpha$ & 1 & + & 16 \\
\hline - faecium ATCC 9790 (group D) & + & 16 & Ala & Glu & Lys & Asp & Ala & $\mathrm{A} 4 \alpha$ & 1 & - & 16 \\
\hline - faecium F-24 (group D) & + & 16 & Ala & Glu & Lys & Asp & Ala & $A 4 \alpha$ & 1 & - & 16 \\
\hline Bifidobacterium breve ATCC 15700 & + & 17 & Ala & Glu & Lys & Gly & Ala & $\mathrm{A} 3 \alpha$ & 1 & + & 17 \\
\hline - adolescentis ATCC 15703 & + & 14,17 & Ala & Glu & Lys $†$ & Asp & Ala & $A 4 \alpha$ & 14 & + & 14 \\
\hline - adolescentis ATCC 15704 & + & 14 & Ala & Glu & Lys $†$ & Asp & Ala & $A 4 \alpha$ & 1,14 & + & 14,17 \\
\hline Collinsella aerofaciens $\ddagger$ ATCC 25986 & + & $8,17,20,21$ & Ala & Glu & Lys & Asp & Ala & $\mathrm{A} 4 \alpha$ & 21 & $+\S$ & 8,26 \\
\hline Collinsella aerofaciens $\ddagger$ ATCC 35085 & - & 8,21 & Ala & Glu & Orn & Asp & Ala & $A 4 \beta$ & 21 & - & 8 \\
\hline Eubacterium limosum ATCC 8486 & - & $20,21,23$ & Ser & Glu & Orn & Lys & Ala & $\mathrm{B} 2 \alpha$ & 21,55 & $-\boldsymbol{9}$ & 26 \\
\hline - alactolyticum ATCC 17927 & - & 21 & Ala & Glu & Dap & & Ala & $\mathrm{A} 1 \gamma$ & 21,56 & + & 25 \\
\hline Lactobacillus fermentum ATCC 14931 & - & $13,19, \mathrm{PS}$ & Ala & Glu & Orn & Asp & Ala & $A 4 \beta$ & 1,13 & - & $13,19, \mathrm{PS}$ \\
\hline - plantarum ATCC 4008 & $?^{* *}$ & 19 & Ala & Glu & Dap & & Ala & $\mathrm{Al} \gamma$ & PS & $? \dagger \dagger$ & $19, \mathrm{PS}$ \\
\hline - plantarum ATCC 8014 & ND & & Ala & Glu & Dap & & Ala & $\mathrm{Al} \gamma$ & 1 & ND & \\
\hline
\end{tabular}

PS, present study; ND, not determined; $\rightarrow$, interpeptide bridge.

${ }^{*}$ Chronic arthritis was not observed by Lehman et al ${ }^{19 ;}$ tintraspecies variation to Orn (PG subtype A4ß) has been reported' ${ }^{14}$; $\ddagger$ formerly Eubacterium aerofaciens ${ }^{38}$; §sensitivity was reported by Severijnen et $a^{17}{ }^{20}$; Iresistance was reported by Severijnen et a ${ }^{20}$; * ${ }^{*}$ chronic arthritis was not observed by Lehman et $a l,{ }^{19}$ whereas in the present study arthritis lasted for 28 days, with no long term CW accumulation in liver; †tresistance was reported by Lehman et al, ${ }^{19}$ but not seen in the present study. 
pneumoniae PG, were found to carry TNF $\alpha$ stimulating activity. ${ }^{9}$ In line with these observations is the demonstration that type A PGs have been reported to be significantly more powerful immunostimulants than type B PGs. ${ }^{1344}$ Likewise, CWs with type A PG activate the complement cascade considerably more effectively than CWs with type B PG. ${ }^{45}$ Furthermore, in our previous study, evidence was obtained to indicate that in strains of Bifidobacterium adolescentis, with intraspecies variation from lysine to ornithine in position three of the stem peptide, a high lysine content is related to the severity of the chronic arthritis. ${ }^{14}$

What might be the mechanism by which a single amino acid in a certain position of the PG stem peptide is decisive for the arthritogenicity of a CW? Recently, a direct comparison of the immunostimulatory power of PGs with or without lysine in position three of the stem peptide was carried out using two strains of Collinsella aerofaciens, one of them being arthritogenic with lysine in the critical position and the other being non-arthritogenic with ornithine replacing lysine. ${ }^{821}$ The CW of the arthritogenic strain was a twofold more potent stimulator of the proinflammatory cytokines TNF $\alpha$ and MCP-1 than the non-arthritogenic CW. After enzyme degradation, the ability of the arthritogenic PG to stimulate production of TNF $\alpha$ and MCP-1 was significantly increased, whereas that of the non-arthritogenic PG was significantly decreased. In other words, after enzyme degradation the arthritogenic PG with lysine in position three had a four- to fivefold stronger stimulatory ability than the enzyme-treated non-arthritogenic PG without lysine in position three.

Table 3 indicates the resistance of different bacterial CWs to lysozyme, in relation to their ability to induce chronic arthritis in the rat. At first sight, it seems that resistance or susceptibility of a CW to lysozyme would bear no correlation to its ability to induce chronic arthritis, even though all CWs causing chronic arthritis, with the exception of Streptococcus faecium, have been reported to be lysozyme resistant (table 3). However, it must be emphasised that the arthritis caused by the CW of Streptococcus faecium is not as long lasting as that induced by the CW of Streptococcus pyogenes, the former subsiding at two months and the latter being still active at four months after the initial CW injection. ${ }^{16}$ On the other hand, it also appears that lysozyme resistance is seen among the CWs not causing chronic arthritis (table 3). These seeming inconsistencies can be fully explained, if it is assumed that lysozyme resistant CWs causing longlasting, chronic arthritis accumulate in large quantities in the liver and spleen, known to be the major reservoirs after an IP CW injection. This assumption is compatible with the following observations: (a) Lysozyme resistant CWs are degraded in vivo considerably less than the lysozyme susceptible ones, leading to the occurrence of large CW fragments and their longer persistence in the tissues. ${ }^{22}{ }^{28}$ The degree of lysozyme resistance has been found to correlate directly with the amount of CW derived muramic acid found in the tissues, ${ }^{14} 1622$ which is also apparent in the present study (fig 3). (b) The liver and spleen act as reservoirs, releasing $\mathrm{CW}$ fragments to the circulation and joint tissues. $^{8} 224647$ (c) In the pathogenesis of chronic bacterial CW arthritis the deposition and persistence of CW degradation products in the synovial tissues is crucial. ${ }^{814224647}$ However, not all CWs deposited are arthritogenic; a decisive factor is whether the CW fragments released are proinflammatory. Ample evidence exists both from animal ${ }^{23}$ 48-50 and human ${ }^{51-53}$ studies to indicate that a variety of microbial components are found in the synovial tissues which do not cause inflammation.

On the basis discussed above it is not difficult to accept the possibility that even lysozyme resistant bacterial CWs may be unable to induce chronic arthritis; they represent PG subtypes other than $\mathrm{A} 3 \alpha$ or $\mathrm{A} 4 \alpha$, and their degradation products are simply not sufficiently proinflammatory, even though they may end up in the joint tissues. In the pathogenesis of chronic bacterial CW arthritis, a PG of an appropriate subtype is required, degradation of which leads to the presence and persistence of phlogistic fragments in the joints, and this seems to be decisive.

\section{ACKNOWLEDGEMENTS}

Minna Suominen and Marja-Riitta Teräsjärvi are gratefully acknowledged for their excellent technical assistance, Seija Lindqvist for taking care of the animals, and Tuula Närä and Tuula Rikalainen for help in preparing the manuscript.

This study was supported by EVO of the Turku University Central Hospital and a grant from the Finnish-Norwegian Medical Foundation.

\section{................}

Authors' affiliations

E Šimelyte, M Rimpiläinen, X Zhang, P Toivanen, Department of Medical Microbiology, Turku Graduate School of Biomedical Sciences and Turku Immunology Centre, Turku University, Turku, Finland

Present addresses: E Šimelyte, Division of Rheumatology, Allergy and Immunology, UCSD School of Medicine, 9500 Gilman Drive, La Jolla, CA 92093, USA (esimelył@ucsd.edu); X Zhang, Department of Immunology and Medicine, University of Toronto, Division of

Rheumatology, Toronto, Canada (xzhang@uhnres.utoronto.ca)

\section{REFERENCES}

1 Schleifer KH, Kandler O. Peptidoglycan types of bacterial cell walls and their taxonomic implications. Bacteriol Rev 1972:36:407-77.

2 Martin SA, Karnovsky ML, Krueger JM, Pappenheimer JR, Biemann K. Peptidoglycans a promotors of slow-wave sleep. I. Structure of the sleep-promoting factor isolated from human urine. J Biol Chem 1984;259:12652-8.

3 Stewart-Tull DES. The immunological activities of bacterial peptidoglycans. Annu Rev Microbiol 1980;34:311-40.

4 Martinez-Martinez L, Timmerman C, Fleer A, Verhoef J. Chemiluminescence of human polymorphonuclear leukocytes after stimulation with whole cells and cell-wall components of Staphylococcus epidermidis. J Med Microbiol 1993;39:196-203.

5 Heumann D, Barras C, Severin A, Glauser MP, Tomasz A. Gram-positive cell walls stimulate synthesis of tumor necrosis factor alpha and interleukin-6 by human monocytes. Infect Immun 1994;62:2715-21

6 Okitsu-Negishi S, Nakano I, Suzuki K, Hashira S, Abe T, Yoshino K. The induction of cardioangitis by Lactobacillus casei cell wall in mice. I. The cytokine production from murine macrophages by Lactobacillus casei cell wall extract. Clin Immunol Immunopathol 1996;78:30-40

7 Chen T, Isomäki P, Rimpiläinen M, Toivanen P. Human cytokine responses induced by Gram-positive cell walls of normal intestina microbiota. Clin Exp Immunol 1999:1 18:261-7.

8 Zhang X, Rimpiläinen M, Simelyte E, Toivanen P. Enzyme degradation and proinflammatory activity in arthritogenic and nonarthritogenic Eubacterium aerofaciens cell walls. Infect Immun 2001;69:7277-84

9 Majcherczyk PA, Langen $H$, Heumann D, Fountoulakis M, Glauser MP, Moreillon P. Digestion of Streptococcus pneumoniae cell wall with its major peptidoglycan hydrolase releases branched stem peptides carrying proinflammatory activity. J Biol Chem 1999;274:12537-43.

10 Schwab JH. Phlogistic properties of peptidoglycan-polysaccharide polymers from cell walls of pathogenic and normal-flora bacteria which colonize humans. Infect Immun 1993:61:4535-9.

11 Cromartie WJ, Craddock JG, Schwab JH, Anderle SK, Yang CH Arthritis in rats after systemic injection of streptococcal cells or cell walls. J Exp Med 1977; 146:1585-602

12 Hazenberg MP, Klasen IS, Kool J, Ruseler-van-Embden JG, Severijnen AJ. Are intestinal bacteria involved in the etiology of rheumatoid arthritis? APMIS 1992;100:1-9.

13 Šimelyte E, Rimpiläinen M, Lehtonen L, Zhang X, Toivanen P. Bacterial cell wall-induced arthritis: chemical composition and tissue distribution of four Lactobacillus strains. Infect Immun 2000;68:3535-40.

14 Zhang X, Rimpiläinen M, Hoffman B, Simelyte E, Aho H, Toivanen P. Experimental chronic arthritis and granulomatous inflammation induced by Bifidobacterium cell walls. Scand J Immunol 2001;54:171-9.

15 Wahl S, Hunt DF, Allen J, Wilder R, Paglia L, Hand A. Bacterial cell wall induced hepatic granulomas. J Exp Med 1986;163:884-902

16 Stimpson SA, Brown RR, Anderle SK, Klapper DG, Clark RL, Cromartie WJ, et al. Arthropathic properties of cell wall polymers from normal flora bacteria. Infect Immun 1986;51:240-9.

17 Severijnen AJ, van Kleef R, Hazenberg MP, van de Merwe JP. Cell wall fragments from major residents of the human intestinal flora induce chronic arthritis in rats. J Rheumatol 1989;16:1061-8.

18 Sartor R, Cromartie W, Powell D, Schwab J. Granulomatous enterocolitis induced in rats by purified bacterial cell wall fragments. Gastroenterology 1985;89:587-95.

19 Lehman TJA, Allen JB, Plotz PH, Wilder RL. Bacterial cell wall composition, lysozyme resistance, and the induction of chronic arthritis in rats. Rheumatol Int 1985;5:163-7. 
20 Severiinen AJ, van Kleef R, Hazenberg MP, van de Merwe JP. Chronic arthritis induced in rats by cell wall fragments of Eubacterium species from the human intestinal flora. Infect Immun 1990;58:523-8.

21 Zhang X, Rimpiläinen $M$, Simelyte E, Toivanen P. What determines arthritogenicity of bacterial cell wall? A study on Eubacterium cell wall-induced arthritis. Rheumatology (Oxford) 2000;39:274-82.

22 Stimpson SA, Esser RE, Cromartie WJ, Schwab JH. Comparison of in vivo degradation of 125l-labeled peptidoglycan-polysaccharide fragments from group A and group D streptococci. Infect Immun 1986:52:390-6.

23 Simelyte E, Rimpiläinen M, Rantakokko K, Lehtonen L, Zhang X, Aho $\mathrm{H}_{\text {, }}$ et al. Tissue distribution and persistence of arthritogenic and non-arthritogenic Eubacterium cell walls. Clin Exp Rheumatol 1999; 17:281-8

24 Simelyte $\mathbf{E}$, Isomäki $\mathrm{P}$, Rimpiläinen $\mathrm{M}$, Zhang $X$, Toivanen $P$. Cytokine production in arthritis susceptible and resistant rats. A study with arthritogenic and non-arthritogenic Lactobacillus cell walls. Scand J Immunol 2001;53:132-8

25 Zhang X. What determines arthritogenicity of a bacterial cell wall? An experimental study on the etiopathogenesis of rheumatoid arthritis using bacteria from normal human intestinal flora. Annales Universitatis Turkuensis 2001;461:1-65

26 Zhang $X$, Rimpiläinen $M$, Simelyte $E$, Toivanen $P$. Characterization of Eubacterium cell wall: peptidoglycan structure determines arthritogenicity. Ann Rheum Dis 2001;60:269-74

27 Lehman TJ, Allen JB, Plotz PH, Wilder RL. Polyarthritis in rats following the systemic injection of Lactobacillus casei cell walls in aqueous suspension. Arthritis Rheum 1983;26:1259-65.

28 Fox A, Brown RR, Anderle SK, Chetty C, Cromartie WJ, Gooder H, et al. Arthropathic properties related to the molecular weight of peptidoglycan-polysaccharide polymers of streptococcal cell walls. Infect Immun 1982;35:1003-10.

29 Lowry OH, Rosebrough NJ, Farr AL, Randall RJ. Protein measurement with the Folin phenol reagent. J Biol Chem 1951;193:265-75.

30 Dubois M, Giles KA, Hamilton JK, Rebers PA, Smith F. Colorimetric method for determination of sugars and related substances. Anal Chem $1956 ; 28: 350-6$

31 Sato K, Saito H, Tomioka H, Yokokura T. Enhancement of host resistance against Listeria infection by Lactobacillus casei: efficacy of cell wall preparation of Lactobacillus casei. Microbiol Immunol 1988;32:1 189-200.

32 Lehtonen L, Eerola E, Oksman P, Toivanen P. Muramic acid in peripheral blood leukocytes of healthy human subjects. J Infect Dis 1995:171:1060-4.

33 Gilbart J, Harrison J, Parks C, Fox A. Analysis of the amino acid and sugar composition of streptococcal cell walls by gas chromatography-mass spectrometry. J Chromatogr 1988;441:323-33.

34 Elmroth I, Fox A, Larsson L. Determination of bacterial muramic acid by gas chromatography-mass spectrometry with negative-ion detection. J Chromatogr 1993;628:93-102.

35 Stimpson SA, Lerch RA, Cleland DR, Yarnall DP, Clark RL, Cromartie WJ, et al. Effect of acetylation on arthropathic activity of group $A$ streptococcal peptidoglycan-polysaccharide fragments. Infect Immun 1987;55:16-23.

36 Hall EA, Knox KW. Properties of polysaccharide and mucopeptide components of the cell wall of Lactobacillus casei. Biochem J 1965;96:310-18.

37 Hungerer KD, Fleck J, Tipper DJ. Structure of the cell wall peptidoglycan of Lactobacillus casei RO94. Biochemistry 1969;8:3567-77.

38 Kageyama A, Benno Y, Nakase T. Phylogenetic and phenotypic evidence for the transfer of Eubacterium aerofaciens to the genus Collinsella as Collinsella aerofaciens gen. nov., comb. nov. Int J Sys Bacteriol 1999;49:557-65.
39 Kohashi O, Pearson CM, Watanabe Y, Kotani S, Koga T. Structura requirements for arthritogenicity of peptidoglycans from Staphylococcus aureus and Lactobacillus plantarum and analogous synthetic compounds. J Immunol 1976;1 16:1635-9.

40 Chang Y-H, Pearson C, Chedid L. Adjuvant polyarthritis. V. Induction by $\mathrm{N}$-acetylmuramyl-L-alanyl-D-isoglutamine, the smallest peptide subunit of bacterial peptidoglycan. J Exp Med 1981;153:1021-6.

41 Tuomanen E, Liu $\mathrm{H}$, Hengstler B, Zak O, Tomasz A. The induction of meningeal inflammation by components of the pneumococcal cell wall. J Infect Dis 1985;151:859-68.

42 Tomasz A, Saukkonen K. The nature of cell wall-derived inflammatory components of pneumococci. Pediatr Infect Dis J 1989;8:902-3.

43 Burroughs $\mathbf{M}$, Rozdzinski E, Geelen S, Tuomanen E. A structure-activity relationship for induction of meningeal inflammation by muramy peptides. J Clin Invest 1993;92:297-302.

44 Kotani S, Tsujimoto M, Koga T, Nagao S, Tanaka A, Kawata S. Chemical structure and biological activity relationship of bacterial cell walls and muramyl peptides. Fed Proc 1986;45:2534-40.

45 Kawasaki A, Takada H, Kotani S, Inai S, Nagaki K, Matsumoto M, e al. Activation of the human complement cascade by bacterial cell walls, peptidoglycans, water-soluble peptidoglycan components, and synthetic muramylpeptides - studies on active components and structural requirements. Microbiol Immunol 1987;31:551-69.

46 Eisenberg R, Fox A, Greenblatt JJ, Anderle SK, Cromartie WJ, Schwab $\mathrm{JH}$. Measurement of bacterial cell wall in tissues by solid-phase radioimmunoassay: correlation of distribution and persistence with experimental arthritis in rats. Infect Immun 1982;38:127-35.

47 Wilder RL, Allen JB, Wahl LM, Calandra GB, Wahl SM. The pathogenesis of group A streptococcal cell wall-induced polyarthritis in the rat. Arthritis Rheum 1983;26:1442-51.

48 Lehman TJA, Allen JB, Plotz PH, Wilder RL. Lactobacillus casei cell wall-induced arthritis in rats: cell wall fragment distribution and persistence in chronic arthritis-susceptible LEW/N and -resistant F344/N rats. Arthritis Rheum 1984:27:939-42.

49 Anderle SK, Allen JB, Wilder RL, Eisenberg RA, Cromartie WJ, Schwab $\mathrm{JH}$. Measurement of streptococcal cell wall in tissues of rats resistant or susceptible to cell wall-induced chronic erosive arthritis. Infect lmmun 1985:49:836-7.

50 Gripenberg-Lerche C, Skurnik M, Toivanen P. Role of YadA-mediated collagen binding in arthritogenicity of Yersinia enterocolitica serotype O:8: experimental studies with rats. Infect Immun 1995:63:3222-6.

51 Zhang L, Nikkari S, Skurnik M, Ziegler T, Luukkainen R, Möttönen T, et al. Detection of herpesviruses by polymerase chain reaction in lymphocytes from patients with rheumatoid arthritis. Arthritis Rheum 1993;36:1080-6.

52 Söderlund $M$, von Essen $R$, Haapasaari J, Kiistala U, Kiviluoto $O$ Hedman K. Persistence of parvovirus B19 DNA in synovial membranes of young patients with and without chronic arthropathy. Lancet 1997;349:1063-5

53 Schumacher HR Jr, Arayssi T, Crane M, Lee J, Gerard H, Hudson AP, et al. Chlamydia trachomatis nucleic acids can be found in the synovium of some asymptomatic subjects. Arthritis Rheum 1999;42:1281-4.

54 Kool J, Gerrits-Boeye MY, Severijnen AV, Hazenberg MP. Immunohistology of joint inflammation induced in rats by cell wall fragments of Eubacterium aerofaciens. Scand J Immuno 1992;36:497-506

55 Guinand M, Ghuysen J, Schleifer K, Kandler O. The peptidoglycan in walls of Butyribacterium rettgeri. Biochemistry 1969:8:200-7.

56 Severin Al, Kokeguchi S, Kato K. Chemical composition of Eubacterium alactolyticum cell wall peptidoglycan. Arch Microbiol 1989;151:34852 